\title{
Pneumococcal meningoencephalitis
}
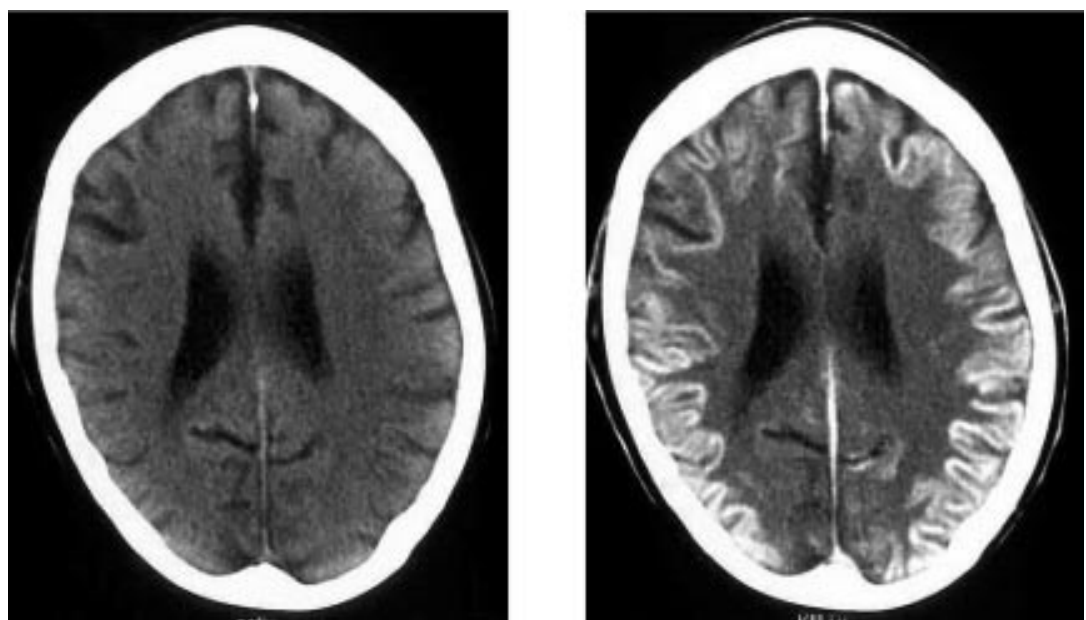

A 43-year-old man with type-1-diabetes developed rapid coma, high temperature $\left(39.7^{\circ} \mathrm{C}\right)$ and nuchal ridigity. History revealed a previous splenectomy and alcohol abuse. The patient was comatose with intact corneal and pupillary reflexes. Cerebrospinal fluid (CSF) showed polymorphonuclear pleocytosis $\left(4500 / \mathrm{cm}^{3}\right.$; normal $\left.<4\right)$, elevated protein $(3700 \mathrm{mg} / \mathrm{L}$; normal < 500), elevated lactat $(16.58 \mathrm{mmol} / \mathrm{L}$, normal < 2.09) and decreased glucose $(20 \mathrm{mg} / \mathrm{dL}$; corresponding blood glucose $79 \mathrm{mg} / \mathrm{dL}$ ). Microscopically gram-positive diplococci and additional exoantigens of streptococcus pneumoniae were detected in the CSF. An unenhanced CT revealed slightly enlarged inner and outer CSF spaces (left). A contrast CT showed pronounced enhancement in the cortical regions (right), suggesting diffuse cortical cerebritis. MRI showed similar findings, but was superimposed by movement artefacts. In repeated EEG no electrical brain activity was detected indicating severe cortex damage, which was also demonstrated by SPECT with strongly reduced cortex perfusion [1]. Antibiotic treatment included ceftriaxon, ampicillin and gentamicin leading to resolution of the inflammatory response. Clinically, the patient developed a persistent vegetative state.

Pneumococcal meningoencephalitis is still a serious infection with high mortality and morbidity rate due to brain injury by inflammatory reaction to the pathogen and septic complications [2,3]. Neuroradiologically, the marked contrast enhancement of the cortex reflects the magnitude of the inflammatory response and disturbance of the bloodbrain barrier. Apart from cortical cerebritis, intraventricular fluid-fluid level, periventricular enhancement, brain oedema, hydrocephalus, vasculitis, sinus thrombosis and cerebral infarction are major complications [2, 4]. In the recent decade knowledge of the interaction of bacterial pathogens with the brain, their entry into the CNS and the complex inflammatory cascade has substantially increased and, in addition to dexamethasone, new anti-inflammatory treatment strategies are under way [2].

Josef G. Heckmann, Michael Schüttler, and Arnd Dörfler

\section{References}

1. Heckmann JG, Lang CJ, Pfau M, Neundörfer B (2003) Electrocerebral silence with preserved but reduced cortical brain perfusion. Eur J Emerg Med 10: 241-243

2. Koedel U, Scheld WM, Pfister HW (2002) Pathogenesis and pathophysiology of pneumococcal meningitis. Lancet Infect Dis 2: 721-736

3. Gamper G, Oschatz E, Herkner H, Paul G, Burgmann H, Janata K, Röggla M, Laggner AN (2001) Sepsis-associated purpura fulminans in adults. Wien Klin Wochenschr 113: 107-112

4. Fink IJ, Danzinger A, Dillon WP, Brant-Zawadzki M, Rechthand E (1984) Atypical CT findings in bacterial meningoencephalitis. Neuroradiology 26: 51-54

Key words: Pneumococcal meningoencephalitis, cerebritis, cranial computed tomography.

Correspondence: Dr. Josef G. Heckmann, Department of Neurology, University Hospital Erlangen, Schwabachanlage 6, 91054 Erlangen, Germany, E-mail: josef.heckmann@neuro.imed.uni-erlangen.de 